\title{
Influence du traitement thermique des milieux de propagation sur le comportement de six levains lactiques
}

\author{
Renée ROY*, J. GOULET * et P. PROVENCHER ** \\ * Département de Sciences et Technologie des Aliments et Centre de Recherche en Nutrition \\ Université Laval, Québec, Canada G1K 7 P4 \\ ** Service des Maladies infectieuses, Centre hospitalier de l'Université Laval \\ Sainte-Foy, Québec, Canada G1K 7P4
}

\section{Résumé}

Deux milieux de propagation à base de poudre de lait écrémé (Lo Heat et Hi Heat) ont subi trois conditionnements à chaud : $88^{\circ} \mathrm{C}$ sans chambrage, $90{ }^{\circ} \mathrm{C}-45 \mathrm{mn}$ et $92{ }^{\circ} \mathrm{C}-60 \mathrm{mn}$. L'évaluation du comportement de six levains lactiques dans ces milieux a révélé la supériorité des deux derniers. Aucune différence significative entre les poudres de lait Lo Heat et Hi Heat n'a pu être mise en évidence quant aux propriétés acidifiantes des levains tant dans le milieu de propagation que dans les laits de grand mélange. Seuls les dénombrements cellulaires dans le milieu Hi Heat se sont avérés significativement supérieurs $(\alpha=0,05)$ à ceux du Lo Heat.

Mots clés : Lait écrémé en poudre - Levains.

\section{Summary}

Effect of heat treatment of growth media on the performance of six lactic starters

Rehydrated commercial skim milk powders (SMP) were used for propagating six (6) cheddar cheese starter cultures. Growth and acidification were estimated through viable cells counts, titratable acidities, $\mathrm{pH}$ and lactic acid production. No significant differences in performance could be observed between Lo heat and Hi heat commercial skim milk powders except for viable counts. Preheating rehydrated SMP's to $90^{\circ} \mathrm{C}$ for $45 \mathrm{mn}$ or $92^{\circ} \mathrm{C}$ for $60 \mathrm{mn}$ as compared to $80^{\circ} \mathrm{C}$ (no holding time) resulted in better growth and acid production for all starters. Under cheese making simulation, no significant differences could be observed in the acid production. Heat denaturation of serum proteins, altered salt equilibrium and Maillard reaction are discussed as to their implications in this behaviour of commercial starter cultures.

Key words : Skim milk powder - Starters - Cheddar. 


\section{Introduction}

Il est reconnu que les streptocoques lactiques sont des organismes à exigences nutritives complexes. Le lait étant le substrat le plus communément utilisé pour la croissance des levains, il doit être d'une haute qualité nutritive, exempt d'antibiotiques et microbiologiquement peu contaminé. Malgré ces exigences, les laits devant servir de milieux de propagation doivent subir un traitement thermique relativement poussé ayant comme principaux objectifs : a) la destruction de la flore banale non sporulée; $b$ ) la destruction des substances inhibitrices naturellement présentes ou accidentellement ajoutées ; $c$ ) la désaération ; d) l'abaissement du potentiel rédox et $e$ ) l'amélioration des qualités nutritives de la fraction protéique pour la croissance des levains (Greene et Jezeski, 1957 b). Cependant, l'intensité du traitement thermique appliqué au lait aurait un effet sur le comportement ultérieur du levain dans ce milieu (Feldstein et Westhoff, 1979).

Auclair et Portmann (1955) ont aussi mis en évidence un comportement altéré de souches pures de Streptococcus lactis et Streptococcus cremoris cultivées dans des laits (crus et écrémés) chauffés à différentes températures. Puisque la plupart des levains commerciaux sont constitués d'un mélange de souches, on peut présumer, à la suite de Petterson (1975) et Gilliland (1977), qu'ils sont fortement influencés par les variations de composition du milieu de propagation et du lait dans lesquels ils sont ensemencés pour la mise en œuvre fromagère.

Etant donné l'importance technique du problème, particulièrement dans les fabrications fromagères nécessitant l'utilisation de ferments mixtes ou multiples et des périodes de maturation prolongées, nous avons entrepris une étude reproduisant le plus fidèlement possible les conditions d'utilisation en atelier.

A partir des résultats d'une enquête menée auprès de neuf fromageries québécoises (Goulet et al., 1981), nous avons comparé deux modes extrêmes de traitement thermique du milieu de propagation $\left(88^{\circ} \mathrm{C}\right.$ sans chambrage et $92{ }^{\circ} \mathrm{C}$, $60 \mathrm{~min})$ à celui d'une "bonne pratique industrielle $\left(90^{\circ} \mathrm{C}, 45 \mathrm{~min}\right)$ pour la propagation de six levains à cheddar. Deux milieux à base de poudre de lait (Lo Heat et Hi Heat) ont été évalués selon chacun des modes.

\section{Matériel et méthodes}

\section{Préparation des inoculums}

Six cultures mixtes commerciales communément utilisées par l'industrie fromagère québécoise ont été retenues : MAR-3 et N13H (Agropur, Granby, Québec), 91 et 253 (Chr. Hansens' Lab., Ltd., Milwaukee, WI) et les levains WP et OS (Miles Lab., division Marschall, Madison, WI). Les cultures mères ont été préparées et congelées selon le protocole déjà décrit (RoY et GouLET, 1986).

\section{Milieu de culture}

Deux poudres de lait écrémé LH (Lo Heat, Aliments Delisle, Boucherville, Québec) et HH (Hi Heat, Agrinove, Sainte-Claire, Québec) réhydratées à $12 \%$ 
E.S.T. ont subi trois traitements thermiques : $88^{\circ} \mathrm{C}$ sans chambrage, $90^{\circ} \mathrm{C}$ 45 min et $92^{\circ} \mathrm{C}-60 \mathrm{~min}$. Après refroidissement, les milieux ont été conservés 12 à $15 \mathrm{~h}$ à $4{ }^{\circ} \mathrm{C}$ avant d'être utilisés.

\section{Conditions de culture}

Les fermentations ont été réalisées dans des erlenmeyers stériles de $500 \mathrm{~mL}$ auxquels on a ajouté aseptiquemet $247,5 \mathrm{~mL}$ des milieux de propagation, chauffés et préalablement équilibrés à $22^{\circ} \mathrm{C}$, et $2,5 \mathrm{~mL}$ des levains soumis à l'étude. L'incubation se poursuivait à $22^{\circ} \mathrm{C}$ sans agitation pendant $11 \mathrm{~h} 15$ à $13 \mathrm{~h}$ selon les cultures utilisées (Roy et Goulet, 1986). Au terme de cette période, les fioles ont été rapidement refroidies et conservées à $4{ }^{\circ} \mathrm{C}$ pour une période n'excédant pas $15 \mathrm{~h}$.

Dans le but de reproduire les premières étapes d'une production fromagère, les cultures ont ensuite été ensemencées $(1 \% \mathrm{v} / \mathrm{v})$ dans du lait frais pasteurisé et homogénéisé de grand mélange, équilibré à $31^{\circ} \mathrm{C}$. L'incubation se poursuivait sans agitation pendant $4 \mathrm{~h}$ à $31^{\circ} \mathrm{C}$.

\section{Echantillonnage}

Des prélèvements ont été effectués au moment de l'inoculation et au terme de chacune des fermentations pour l'évaluation du $\mathrm{pH}$, de l'acidité titrable, de la population bactérienne viable et de l'acide lactique.

\section{pH et acidité titrable}

Les mesures du $\mathrm{pH}$ et de l'acidité titrable ont été réalisées au moyen d'un titrimètre automatique (TTT-2 Radiometer, Copenhague, Danemark) dont le point de consigne avait été ajusté à 8,6 , point de virage de la phénolphtaléine. Une solution de $\mathrm{NaOH} \mathrm{N/9}$ a été utilisée comme neutralisant.

\section{Cellules viables}

Les dénombrements des cellules viables ont été effectués sur gélose Elliker (Elliker broth $+1,5 \%$ Bacto-agar, Difco) suivant les dilutions décimales appropriées dans de l'eau peptonée $(0,1 \%$ Bacto-peptone, Difco) stérile. Les boîtes de Petri ont été incubées $60 \mathrm{~h}$ à $22^{\circ} \mathrm{C}$ avant d'être lues sur compteur automatique (Artek Counter modèle 880, Artek Systems Corp., N.Y.).

\section{Acide lactique}

Le dosage de l'acide lactique a été effectué selon la méthode de LAWRENCE (1975) à partir d'échantillons dilués $1: 1000$ dans de l'eau désionisée. La courbe étalon a été établie à partir de valeurs situées entre 0 et $10 \mu \mathrm{g}$ de lactate/mL. 


\section{Analyse statistique}

Les essais ont été répétés 2 fois et les résultats obtenus ont fait l'objet d'une analyse de variance de type factoriel à partir des logiciels SAS (Statistical Analysis System, Helwig et Council, 1979) et BMDP (Biomedical Computer Programs, DiXon et BRown, 1979).

\section{Résultats}

La relation hautement significative $(\alpha=0,01)$ liant les traitements thermiques à la multiplication cellulaire et à l'acidification des milieux de propagation par six levains à cheddar est mieux décrite par une régression linéaire que quadratique (tabl. I). L'analyse statistique a également révélé des différences haute-

\section{TABLEAU I}

Influence de deux types de milieux de propagation et trois traitements thermiques sur la croissance $(12 \mathrm{~h})$ et l'activité acidifiante $(12 \mathrm{~h})$ de six levains lactiques : valeurs $F$ obtenues avec analyse de variance

Effect of two types of growth medium and three heat treatments on the growth and activity of six lactic starters : analysis of variance ( $F$ ratio)

\begin{tabular}{|c|c|c|c|c|c|}
\hline Facteur & d. 1 . & $\begin{array}{c}\text { Acidité } \\
\text { développée } \\
(\Delta A)\end{array}$ & $\begin{array}{l}\text { Baisse } \\
\text { du } \mathrm{pH} \\
(\Delta \mathrm{pH})\end{array}$ & $\begin{array}{l}\text { Croissance } \\
\text { cellulaire } \\
(\Delta b / \mathrm{mL})\end{array}$ & $\begin{array}{c}\text { Acide lactique } \\
\text { produit } \\
\text { (هlactate) }\end{array}$ \\
\hline Levains & 5 & $65 * *$ & $108 * \star$ & $112 \star \star t$ & $11 * \pi$ \\
\hline $\begin{array}{l}\text { Milieux de } \\
\text { propagation }\end{array}$ & 1 & $149 * *$ & $161^{\star \star}$ & $30 * \star$ & $0-$ \\
\hline $\begin{array}{l}\text { Traitements } \\
\text { thermiques }\end{array}$ & 2 & $419 * \pi$ & $813 * *$ & $31 \div *$ & $36 * *$ \\
\hline linéaire & 1 & $736 * \pi$ & $1405 * \pi$ & $49 * *$ & $72 * *$ \\
\hline quadrat ique & 1 & $102 \star \star$ & $221 * \hbar$ & $14 \pi \pi$ & $1-$ \\
\hline Levains $x$ milieux & 5 & $3 *$ & $10 * \pi$ & $4 \pi *$ & $1-$ \\
\hline $\begin{array}{l}\text { Levains } x \\
\text { traitements }\end{array}$ & 10 & $10 * \star$ & $23 * \pi$ & $3^{\text {** }}$ & $2-$ \\
\hline $\begin{array}{l}\text { Milieux } x \\
\text { traitements }\end{array}$ & 2 & $126 * *$ & $300 * \pi$ & $16 * *$ & $67 * *$ \\
\hline $\begin{array}{l}\text { Milieux } x \\
\text { levains } x \\
\text { traitements }\end{array}$ & 10 & $6 * \pi$ & $14 * *$ & $1-$ & $3 \div$ \\
\hline
\end{tabular}

Légende :

\#* significatif a $\alpha=0,01$

* significatif a $\alpha=0,05$

- non significatif 
ment significatives $(\alpha=0,01)$ entre les levains au cours de leur propagation dans des milieux à base de lait. De plus, les deux milieux de propagation évalués différaient significativement $(\alpha=0,01)$ l'un de l'autre.

Notons aussi les interactions « levains $\times$ milieux », «levains $\times$ traitements, 《 milieux $\times$ traitements et « milieux $\times$ levains $X$ traitements », qu'il apparaît difficile de justifier autrement que par un comportement très hétérogène des levains en réponse aux divers paramètres de l'étude.

Les données détaillées (fig. 1) permettent de mieux voir et de comparer le comportement des levains dans les conditions expérimentales étudiées. On peut y voir qu'un milieu à base de poudre $\mathrm{HH}$, traité à $88^{\circ} \mathrm{C}$ sans chambrage, a un effet plus défavorable sur les propriétés acidifiantes (acidité développée et baisse du $\mathrm{pH}$ ) des levains que ceux traités à $90{ }^{\circ} \mathrm{C}, 45 \mathrm{~min}$, et $92{ }^{\circ} \mathrm{C}, 60 \mathrm{~min}$ (fig. $1 \mathrm{a}$ et 1c). L'effet n'est toutefois pas aussi évident pour le milieu LH traité de la même façon (fig. $1 \mathrm{~b}$ et $1 \mathrm{~d}$ ). Pour la multiplication cellulaire, le traitement thermique des milieux $\mathrm{LH}$ et $\mathrm{HH}$ à $88^{\circ} \mathrm{C}$ a un effet négatif sur tous les levains excepté le $\mathrm{n}^{\circ} 253$ (fig. 1e et $1 \mathrm{f}$ ).

L'analyse statistique des résultats obtenus en simulation fromagène (tabl. II) indique que le traitement thermique subi par les milieux de propagation a eu

\section{TABLEAU II}

Influence du milieu de propagation et de son traitement thermique sur la croissance $(4 \mathrm{~h})$ et l'activité acidifiante $(4 \mathrm{~h})$ de six levains lactiques dans un lait frais de grand mélange : valeurs $F$ obtenues avec analyse de variance

Effect of the growth medium and its heat treatment on the growth and activity of six lactic starters in bulk raw milk : analysis of variance ( $F$ ratio)

\begin{tabular}{|c|c|c|c|c|c|}
\hline Facteur & d.1. & $\begin{array}{c}\text { Acidité } \\
\text { développée } \\
(\triangle A)\end{array}$ & $\begin{array}{l}\text { Baisse } \\
\text { du } \mathrm{pH} \\
(\Delta \mathrm{pH})\end{array}$ & $\begin{array}{l}\text { Croissance } \\
\text { cellulaire } \\
(\Delta \mathrm{b} / \mathrm{mL})\end{array}$ & $\begin{array}{c}\text { Acide lactique } \\
\text { produit } \\
\text { (olactate) }\end{array}$ \\
\hline Levains & 5 & $49^{\text {k* }}$ & $88 * *$ & $22 * \hbar$ & $4 * \hbar$ \\
\hline $\begin{array}{l}\text { Milieux de } \\
\text { propagation }\end{array}$ & 1 & $1-$ & $3-$ & $4 \pi$ & $0-$ \\
\hline $\begin{array}{l}\text { Traitements } \\
\text { thermiques }\end{array}$ & 2 & $52 * *$ & $153 * *$ & $6 * *$ & $2-$ \\
\hline lineaire & 1 & $67^{* *}$ & $191 \div *$ & $3-$ & $1-$ \\
\hline quadratique & 1 & $37 * \pi$ & $116 * *$ & $8 * *$ & $2-$ \\
\hline Levains $x$ milieux & 5 & $2-$ & $2-$ & $1-$ & $1-$ \\
\hline $\begin{array}{l}\text { Levains } x \\
\text { traitements }\end{array}$ & 10 & $1-$ & $3^{* \star}$ & $1-$ & $1-$ \\
\hline $\begin{array}{l}\text { Milieux } x \\
\text { traitements }\end{array}$ & 2 & $2-$ & $2-$ & $1-$ & $6 * \pi$ \\
\hline $\begin{array}{l}\text { Milieux } \times \text { levains } \times \\
\text { traitements }\end{array}$ & 10 & $5^{ \pm 1 *}$ & $9 \approx=$ & $1-$ & $1-$ \\
\hline
\end{tabular}

Légende:

th significatif a $\alpha=0,01$

* significatif à $\alpha=0,05$

- non significatif 

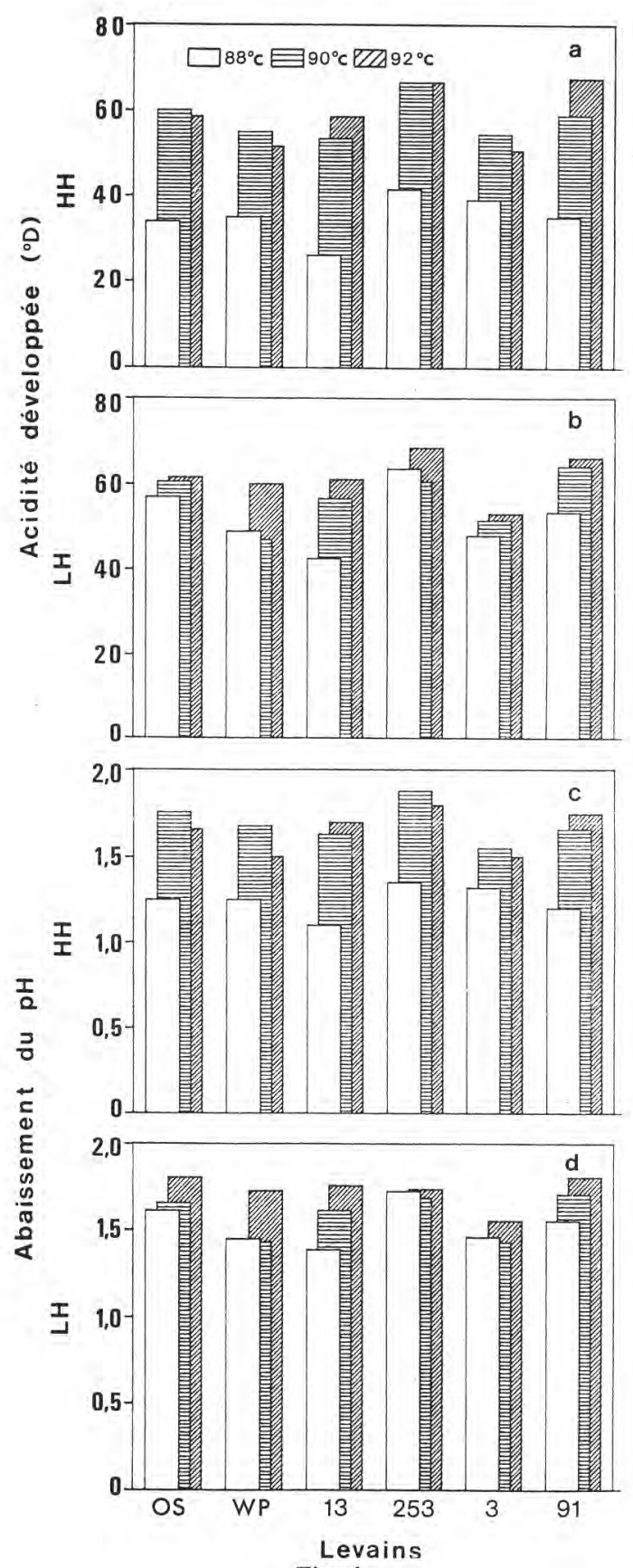

Fig. 1

Influence de deux types de milieux de propagation ( $L H$ et $H H$ ) et trois traitements thermiques $\left(88^{\circ} \mathrm{C}\right.$ sans retenue, $90^{\circ} \mathrm{C}-45 \mathrm{~min}$ et $\left.92^{\circ} \mathrm{C}-60 \mathrm{~min}\right)$ sur le comportement de six levains lactiques $(12 \mathrm{~h})$ : 

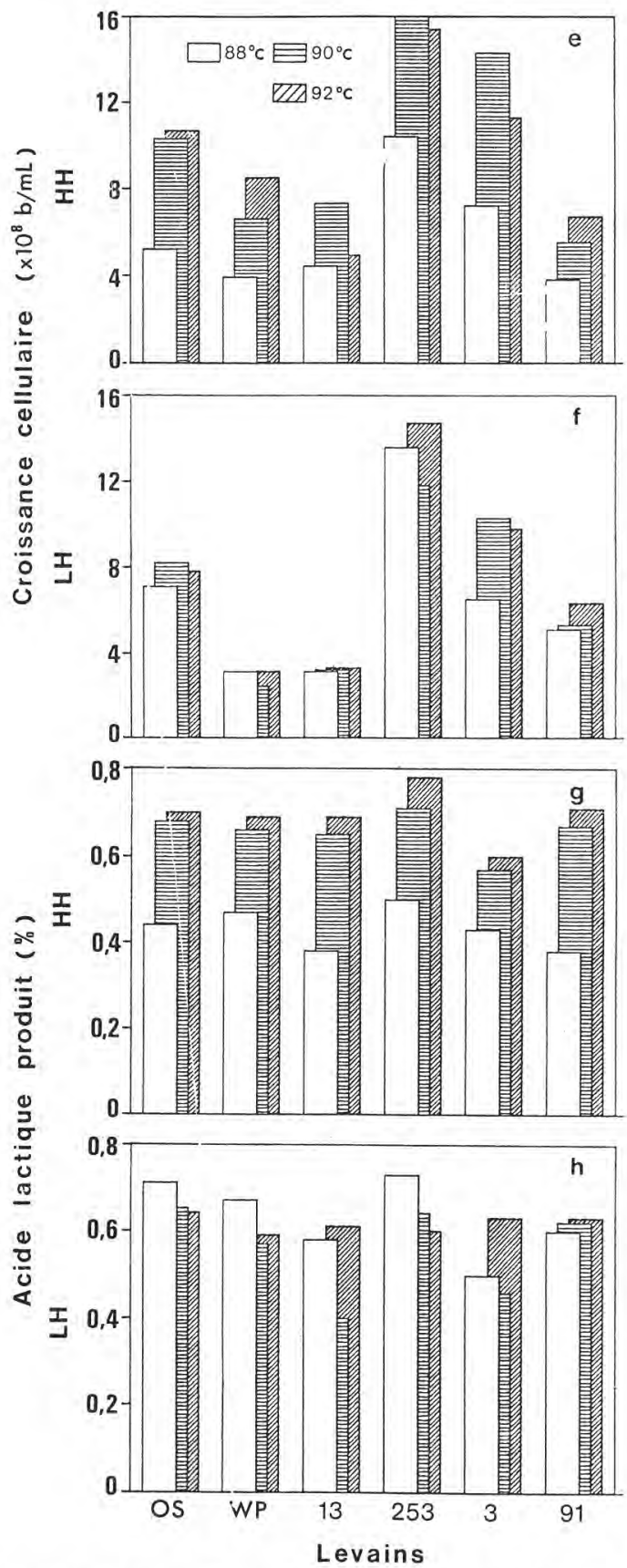

Effect of two types of growth medium $(\mathrm{LH}$ and $\mathrm{HH})$ and three heat treatments $\left(88^{\circ} \mathrm{C}\right.$ without holding time, $90^{\circ} \mathrm{C}-45 \mathrm{~min}$ and $92^{\circ} \mathrm{C}-60 \mathrm{~min}$ ) on the performance of six lactic starters $(12 \mathrm{~h})$ :

acidification ( $a$ and $b$ );

cell growth (e and $f$ );

$p H$ decrease ( $c$ and $d)$;

lactic acid production ( $g$ and $h$ ). 

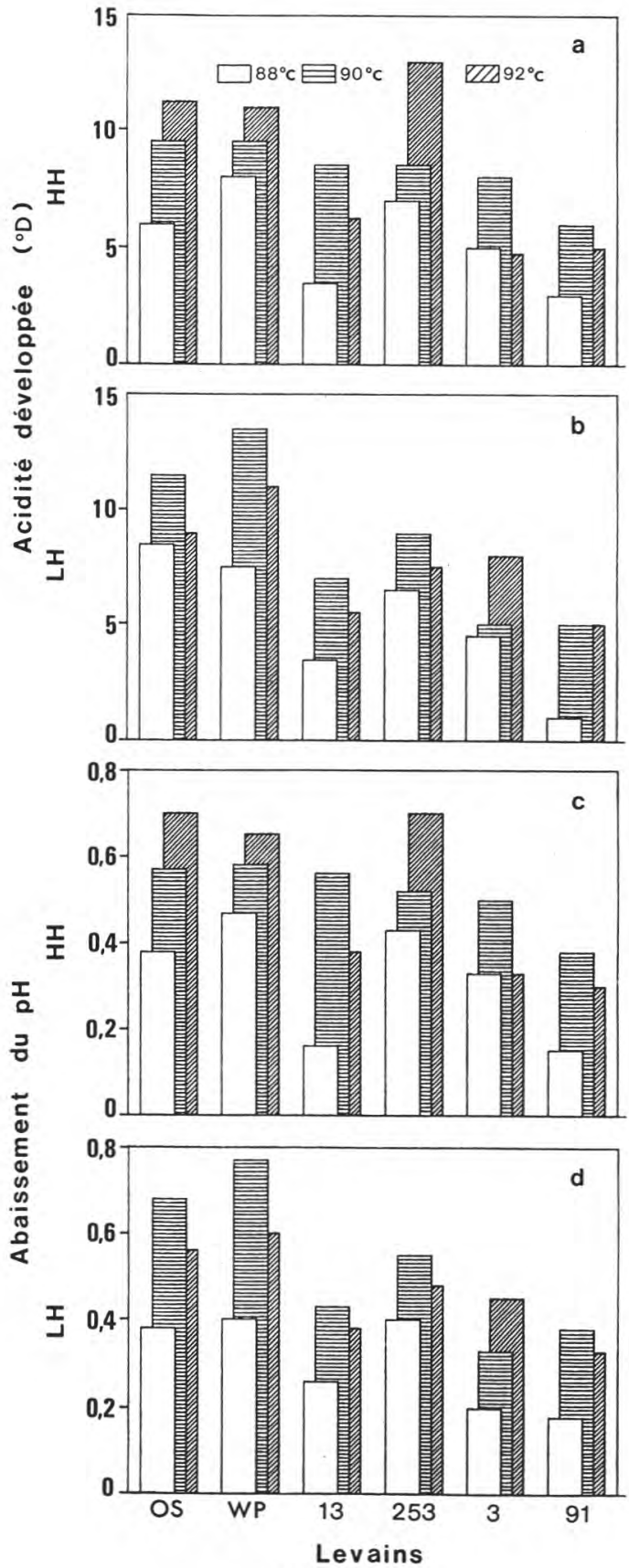

Fig. 2

Influence du milieu de propagation et de son traitement thermique sur le comportement de six levains lactiques dans un lait frais de grand mélange $(4 \mathrm{~h})$ :

acidification ( $a$ et $b$ ) ;

abaissement du pH (c et d); croissance cellulaire ( $e$ et $f)$;

production d'acide lactique ( $g$ et $h)$. 

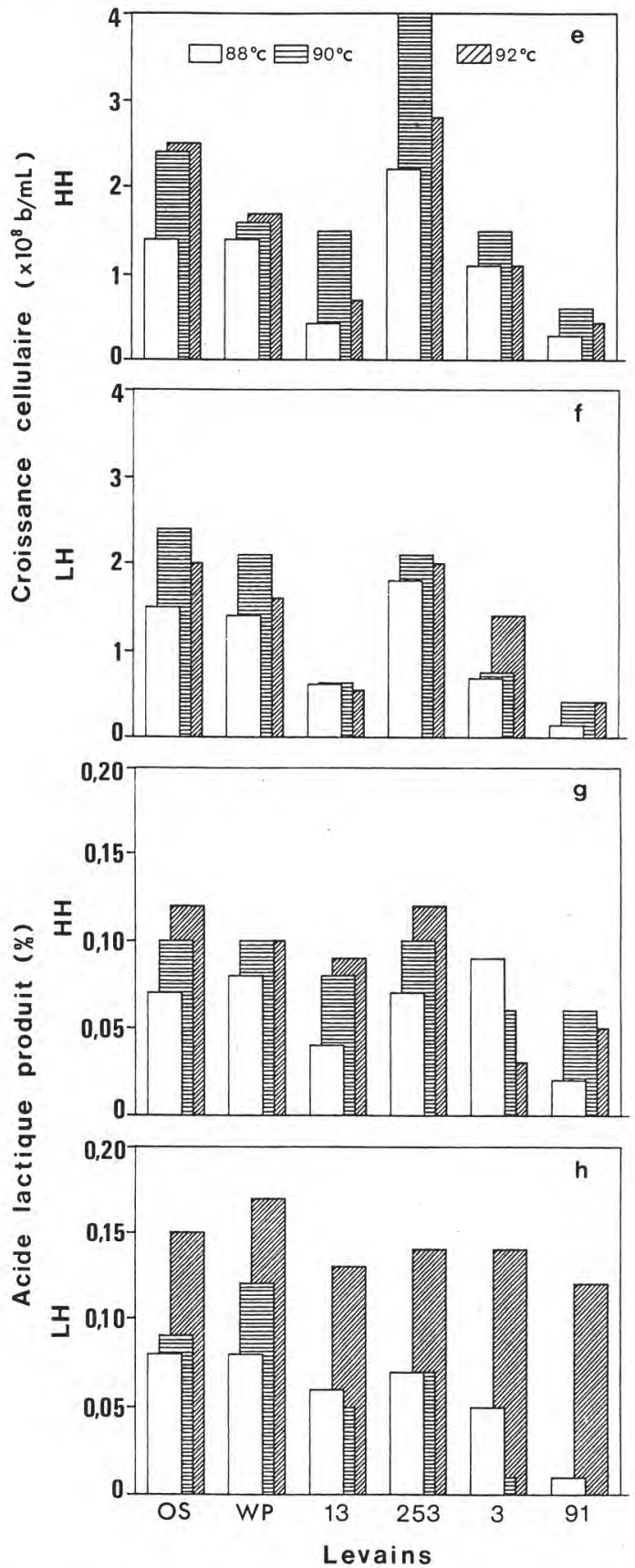

Effect of the growth medium and its heat treatment on the performance of six lactic starters in bulk raw milk (4h): 
des effets hautement significatifs $(\alpha=0,01)$ sur la performance des levains, à la suite de leur transfert dans un lait frais de grand mélange. Une interaction triple « milieux $\times$ levains $\times$ traitements » a été mise en évidence, dont l'explication tient probablement encore au comportement très hétérogène $(\alpha=0,01)$ des divers levains dans les milieux traités différemment.

Le traitement thermique le moins prononcé $\left(88^{\circ} \mathrm{C}\right.$ sans chambrage) a atténué le pouvoir acidifiant de tous les levains en lait frais (fig. 2a, 2d). Dans l'ensemble, le conditionnement à $90{ }^{\circ} \mathrm{C}, 45 \mathrm{mn}$, qualifié de «bonne pratique industrielle », semble donner un comportement identique à celui obtenu avec un traitement thermique plus rigoureux $\left(92^{\circ} \mathrm{C}, 60 \mathrm{mn}\right)$, que le milieu de propagation soit à base de lait $\mathrm{LH}$ ou de lait $\mathrm{HH}$. La multiplication cellulaire ne semble pas affectée de la même façon que le pouvoir acidifiant des levains en réponse au traitement thermique du milieu de propagation (fig. $2 \mathrm{e}$ et $2 \mathrm{f}$ ). Les dénombrements les plus élevés ont été obtenus dans les milieux à base de poudre $\mathrm{HH}$ chauffés à $90^{\circ} \mathrm{C}$, $45 \mathrm{mn}$. Une intensification du traitement thermique du milieu n'a pas eu d'effet significatif sur la production d'acide lactique en simulation fromagère. Pour le milieu $\mathrm{LH}$, l'élévation de la température de $88^{\circ} \mathrm{C}$ sans retenue à $0^{\circ} \mathrm{C}, 45 \mathrm{mn}$ n'a pas eu d'effet marqué sur la production d'acide. Par ailleurs, le traitement à $92{ }^{\circ} \mathrm{C}, 60 \mathrm{mn}$ a eu un effet stimulant sur la production d'acide lactique pour l'ensemble des levains (fig. $2 \mathrm{~g}$ et $2 \mathrm{~h}$ ).

\section{Discussion et conclusion}

Nos résultats démontrent clairement que le traitement thermique d'un milieu de propagation à base de poudre de lait écrémé a une influence hautement significative sur les caractéristiques de croissance et d'acidification des levains lactiques commerciaux : cet effet se prolonge même au cours des premières étapes de la fabrication fromagère tel que mis en évidence par les essais en lait frais de grand mélange (tabl. II, fig. 2). Des trois traitements thermiques étudiés, deux se sont avérés comparables dans leur pouvoir stimulant à l'égard de six levains lactiques commerciaux $\left(90^{\circ} \mathrm{C}, 45 \mathrm{mn} ; 92^{\circ} \mathrm{C}, 60 \mathrm{mn}\right)$.

A l'instar des observations de Greene et JEzesKi (1957 a), nos résultats suggèrent que l'activité des levains est étroitement liée à l'intensité des traitements thermiques utilisés lors de la fabrication des types de poudre Lo Heat et Hi Heat. Cet effet s'ajoute à celui du traitement des poudres réhydratées tel que nous venons de le démontrer. Une plus grande dénaturation des protéines du sérum contribue vraisemblablement à accroitre l'assimilabilité de certaines fractions azotées par les streptocoques et à stimuler la croissance de ces derniers.

Les données rapportées par LARSON et RoLleRI (1955) sur la dénaturation thermique des protéines sériques confirment l'équivalence des traitements à $90^{\circ} \mathrm{C}$ et $92{ }^{\circ} \mathrm{C}$ pour des retenues supérieures à $30 \mathrm{mn}$ : la dénaturation sous de telles conditions est quasi complète pour toutes les protéines sériques ( $\beta$-lactoglobuline, $\alpha$-lactalbumine, immuno-globulines et albumine du sérum) à l'exception de la fraction protéose-peptone. Par ailleurs, en s'inspirant des travaux de HARLAND et al. (1953), on peut estimer à moins de $50 \%$ le degré de dénaturation des protéines sériques soumises au traitement à $88^{\circ} \mathrm{C}$. 
L'équilibre salin du lait subit lui aussi les contrecoups des traitements thermiques. Les constantes de solubilité des sels phosphocalciques sont particulièrement affectées par la température (Holt et al., 1925 ; BASSETT, 1958 ; Boulet et MARIER, 1960) et environ $50 \%$ du calcium et $20 \%$ des phosphates solubles deviennent non ultrafiltrables dans un lait chauffé à $93^{\circ} \mathrm{C}$ (ROSE et Tessier, 1959).

Ces changements sont toutefois réversibles dans une proportion de 75 à $90 \%$ lors du refroidissement et il est peu probable que la perturbation de l'équilibre phosphocalcique du lait puisse être liée aux changements de comportement des ferments cultivés dans des laits plus ou moins chauffés.

Par ailleurs il en est tout autrement du lactose dont la réactivité vis-à-vis des protéines du lait a été largement étudiée (PAtTon et Josephson, 1949; PatTon, 1955). Outre la réaction de Maillard qui ne nécessite qu'une faible énergie d'activation et qui est autocatalytique (NICKERSON, 1980), il faut considérer aussi la caramélisation directe du lactose comme source de produits susceptibles d'interférer avec le développement de ferments dans des laits chauffés à haute température. Ferreti et Flanagan (1971) ont détecté près de 80 produits de réaction provenant d'un mélange de caséine et de lactose entreposé 8 jours à $80^{\circ} \mathrm{C}$ sous $75 \%$ d'humidité relative. Du point de vue nutritif, la destruction des acides aminés basiques tels la lysine, l'histidine et l'arginine lors de la réaction de Maillard pourrait aussi expliquer certains effets sur la croissance (fig. 1e et 1f) de quelques ferments commerciaux : toutefois aucune tendance générale ne permet de distinguer nettement l'un ou l'autre milieu de propagation ( $\mathrm{LH}$ versus $\mathrm{HH}$ ).

L'ensemble des données rapportées à la figure 1 laisse voir un effet négatif du chauffage à $88^{\circ} \mathrm{C}$ sur la performance globale des ferments en milieu $\mathrm{HH}$. L'effet observé touche autant la croissance cellulaire (fig. 1e) que les mesures d'acidité titrable (fig. 1a), d'abaissement de $\mathrm{pH}$ (fig. 1c) et de production d'acide lactique (fig. 1g). Un tel comportement suggère que l'effet observé est principalement imputable à un ralentissement de croissance avec comme répercussion immédiate, une production inférieure d'acide lactique. La grande similarité des profils d'acidité développée, d'abaissement de $\mathrm{pH}$ et d'acide lactique produit renforce l'hypothèse d'un effet lié fortement à la production d'acide lactique. II est peu vraisemblable que cet effet soit lié à une activité protéolytique modifiée des ferments puisque le pouvoir tampon des milieux, tel qu'estimé par les mesures d'acidité développée et d'abaissement de $\mathrm{pH}$, n'a pas été altéré de façon marquée. En effet les différences d'acidité développée entre les milieux LH et HH (fig. 1a et 1 b) sont équivalentes aux différences d'acide lactique mesurées entre les mệmes milieux (fig. $1 \mathrm{~g}$ et $1 \mathrm{~h}$ ) au terme de la croissance cellulaire.

Le transfert des ferments des milieux de propagation $\mathrm{LH}$ et $\mathrm{HH}$ du lait frais de grand mélange a permis d'atténuer mais non d'éliminer complètement l'effet négatif du traitement thermique à $88^{\circ} \mathrm{C}$ (fig. 2). Les différences sont particulièrement apparentes pour les ferments préalablement cultivés en milieu LH : un tel comportement suggère qu'une attention toute particulière devrait être consacrée à l'étape de propagation des ferments puisque des effets de ralentissement d'acidification peuvent se répercuter jusque dans les premières étapes de la production fromagère.

Cette étude fournit la preuve que les poudres de lait $\mathrm{LH}$ et $\mathrm{HH}$ peuvent être utilisées indifféremment dans la préparation des milieux utilisés pour la propaga- 
tion des levains. Il faut cependant s'assurer que les deux types de poudre répondent aux mêmes normes de qualité quant à l'absence d'agents inhibiteurs (antibiotiques) et de contaminants bactériens indésirables.

Reçu le 19 août 1985.

Accepté pour publication le 15 juillet 1986.

\section{Remerciements}

Cette recherche a été réalisée grâce à un contrat de la Commission canadienne du lait (OSU81-00310). Nous tenons à remercier le Dr D.A. EMMONS (Agriculture Canada) pour ses précieux conseils.

\section{Références bibliographiques}

Auclair J.E., Portmann A., 1955. Influence du chauffage du lait sur le développement des bactéries. I. Croissance des bactéries lactiques dans des laits chauffés à des températures variables. Ann. Technol. Agric., 4, 121-131.

BASSET H.J., 1958. The phosphates of calcium. Part V. Revision of the earlier space diagram. J. Chem. Soc., 3, 2949-2955.

Bovlet M., MARIER J.R., 1960. Solubility of tricalcium citrate in solutions of variable ionic strenght and in milk ultrafiltrates. J. Dairy Sci., 43, 155-164.

DIXON W.J., BROWN M.B., 1979. BMDP Biochemical computer programs P series. Univ. California Press, Los Angeles.

FELDSTEIN F.J., WESTHOFF D.C., 1979. The influence of heat treatment of milk on starter activity : what UHT ? Cult. Dairy Prod. J., 14, 11-15.

Ferreti A., Flanagan V.P., 1971. The lactose-casein (Maillard) browning system : volatile components, J. Agric. Food Chem., 19, 245-249.

GILLILAND S.E., 1977. Preparation and storage of concentrated cultures of lactic strepococci. J. Dairy Sci., 60, 805-809.

GoUlet J., BoY R., SAINT-CLAIR P.M., 1981. Ferments lactiques et production fromagère ; importance de la régie. Contrat OSU80-00335, Commission canadienne du lait, Agriculture Canada, Ottawa, Ontario.

GREENE V.W., JEZESKI J.J., 1957 a. Studies on starter metabolism. I. The relationship between starter activity and the predrying heat history of reconstituted nonfat dry milk solids. J. Dairy Sci., 40, 1046-1052.

GREENE V.W., JEZESKI J.J., 1957-b. Studies on starter metabolism. II. The influence of heating milk on the subsequent response of starter cultures. J. Dairy Sci., 40, 1053-1061.

HaRland H.A., Coulter S.T., Townley V.H., Jenness R., 1953. The denaturation of milk serum proteins at temperatures ranging from 180 to $290^{\circ}$ F. J. Dairy Sci., 36, 568-569.

Helwig J.T., Council K.A., 1979. SAS user's guide. 1979 edition. Cary, North Carolina.

HoLt L.E., LA MeR J.K., Chown H.B., 1925. Studies in calcification. I. The solubility product of secondary and tertiary calcium phosphate under various conditions. J. Biol. Chem., $64,509-565$.

LARSoN B.L., Rolieri G.D., 1955. Heat denaturation of the specific serum proteins in milk. J. Dairy Sci., 38, 351-360. 
LaWrence A.J., 1975. Determination of lactic acid in cream. Aust. J. Dairy Technol., 30, $14-15$.

NiCKERSON T.A., 1980. Lactose in "Fundamentals of Dairy Chemistry ", edited by Webb B.H., Johnson A.H. and Alford J.A., The AVI Publishing Company Inc., Westport.

Patton S., Josephson D.V., 1949. Observations on the application of the nitroprusside test to heated milk. J. Dairy Sci., 32, 398-405.

Patron S., 1955. Browning and associated changes in milk and its products : a review. J. Dairy Sci., 38, 457-478.

PeTtERSON H.E., 1975. Studies on batch production of bacterial concentrates from mixed species lactic starters. Appl. Microbiol., 29, 133-140.

Rose D., Tessier H., 1959. Composition of ultrafiltrates from milk heated at 80 to $230^{\circ}-\mathrm{F}$ in relation to heat stability. J. Dairy Sci., 42, 969-980.

Roy R., Goulet J., 1986. Influence de quatre milieux de propagation sur le comportement de six levains lactiques mésophiles du commerce. Lait, 67 (1), 41-50. 